\title{
Writing otherwise: A critical cosmopolitan approach to reflecting on writing and reading practices in fiction and non-fiction
}

\begin{abstract}
In reaction to the opening up or redrawing of the world's borders - virtual and real, material and ideological the language of conventional western political communication seems to become increasingly dogmatic and even strident. In this paper, I argue that critical cosmopolitanism provides a framework within which students, teachers, researchers and practitioners can explore contemporary issues represented in the writing of literary fiction as a means of critiquing the limited and limiting vision of such political writing. I outline a critical cosmopolitan orientation to approaching, practising and reviewing writing practices in the global public domain, primarily an ethical and relational endeavour, alert to writers' obligations to (often distant and unknown) others, as well as to the complexity and ambivalence of those relationships. The paper then explores how Lloyd Jones novel, Hand me down world, serves to trouble the text of the Australian Government's 'No to people smuggling' campaign. As a means of disrupting its (non-fiction) other, fiction writing can offer us ethical, political and aesthetic insights into imagining alternative relations between subjects situated within and moving across shifting borders.
\end{abstract}

Keywords: cosmopolitanism, professional writing

\section{Introduction}

In this paper I argue for a critical cosmopolitan orientation to reflecting on and doing writing. Having outlined the conceptual and ethical framework of such an orientation, I aim to demonstrate, as one specific example of a critical cosmopolitan move, that the language of literary fiction can assist us, as teachers, students, researchers and practitioners, in critiquing and reappraising the language of politics, in order to make sense of our ethical obligations to write to and about the other in more responsible and productive ways [1]. Here, I am interested in the jostling of the borders between the language of literature and the language of politics, and how such focus exposes the points of tension between the words, the terms and concepts and the narratives to which they give rise in the texts of politics and literature respectively. This opens up a space by means of which we can interrogate the dogma of present-day politics and the straitjacket of antagonistic political jousting, too often a performance exposing an ethically impoverished communicative impasse.

In a recent paper, Tony Fisher explores the way in which critical art might expose or unsettle the logic of politics, 'at the same time as it resists its gravitational field, its heliotropic influence' (Fisher 2011: 16) [2]. This study is in part inspired by Fisher's investigation of the disturbing of the political by the aesthetic, where the latter confronts, yet resists taking a dogmatic position in its response to, political questions [3]. However, it is my interest in cosmopolitanism and a specifically cosmopolitan orientation to professional and creative writing in learning, teaching and research that, in this paper, frame my focus on the relationship between art and politics, between literary and political modes of expression.

In a contemporary western political environment in which the language of government and public policy are squeezed and shaped to conform to the demands of a media-grab-and tweet-sized news and current affairs cycle, the risks of reducing language use to the combative, the instrumental, the crude and the essentialised are heightened. Indeed, as Turkish fiction writer Elif Shafak points out, "The language of politics is different. "We" and "they", "I" and "other" are the main players in politics. Politicians always create and need an "other" (Shafak 2010). Other writers, including Václav Havel (1990), Zadie Smith (2009) and Chimamanda Ngozi Adichie (2012), have each differently warned us about the stultifying and destructive impacts of a textually diminished politics. However, paradoxically, in an increasingly globalised world in which borders of all kinds are continually being disrupted and redrawn, the language of politics tends to resist relational openness to the other in its (sometimes desperate) efforts to circumscribe and contain ideological as well as national, cultural, social, racial and ethnic borders and oppositions.

In the sections that follow, I explore how a critical cosmopolitan lens exposes the problems of communicating according to an outmoded unidirectional model that tries to discipline and delimit how readers 'see' and make sense of political 'messages'. Further, and by interspersing this discussion with references to a contemporary novel, I show how literary fiction writing, and its capacity to awaken in us our responsibility to care for the other, might further trouble (the borders of its other) non-fiction, professional writing. The texts in question are an extract from a current Australian Government online campaign aimed at discouraging would-be asylum seekers from attempting to reach Australia by boat; and the novel Hand me down world, by Lloyd Jones, narrating the inter-continental journey of a displaced African woman in search of her abducted child, as well as exploring range of character perspectives on the 'illegal immigrant' [4]. 
Importantly, the paper proceeds from the view that the differences between art and politics have been overemphasised and unduly exploited. On one hand the purposes and aims of art-text and political-text are quite clearly different: we could say that the aim of the former is to explore ideas and questions relating to the complexity of human experiences, actions, events and their interaction, while the aim of the latter is to offer singular answers to how best to interpret and manage those experiences, actions, events and their interaction [5]. However, in our encounter with either art or politics, notwithstanding their different cultural positioning, some kind of interplay between producer, text, reader (or viewer) and socio-temporal context is common to both. This is perhaps truer today than ever, when the combination of words and images, their mediation through a range of social media platforms, and the potential for active response to them, characterise the political process (just as they do the mediation of self-consciously artistic processes, products and performances). Nikos Papastergiadis discusses the confluence of art and politics along these lines in his discussion of aesthetic cosmopolitanism, and particularly the central role of imagination in this practice:

The recent tendencies in art ... point towards a different mode of engagement with the process of social transformation, and in these instances the medium of art is not confined to a fixed object. This mode of political engagement and the current play with nonmaterial media compels a reconfiguration of the relationship between art and politics. (Papastergiadis 2012: 225)

By extension, French theorist Jacques Rancière argues that realist literature 'does a kind of side-politics or metapolitics' (Rancière 2004: 19), and it is just this side-politics or meta-politics of literature that I wish to co-opt as an ethical cosmopolitan move in relation to professional writing practice and critique. A critical cosmopolitan orientation, one of whose tasks is to interrogate the rationale for the construction of borders and boundaries, can thus be harnessed to challenge the conventional distinctions (between art and politics) outlined above, and to help identify the corresponding preoccupations of as well as the points of tension between different kinds of writing: political, non-fiction writing on the one hand and creative, particularly fiction, writing on the other. For student writers, teachers, researchers and practitioners this also supports a framework for reflecting on how writing in a global context poses particular demands and responsibilities on the processes of engaging (with) others.

\section{Critical cosmopolitanism and its pertinence for writing [6]}

The critical turn in cosmopolitanism is pertinent to doing writing and deliberating on writing practices in the globalised context of the twenty-first century. This orientation appreciates the social, political, economic and cultural ambivalences, obstacles, inequities and competing interests involved in the normative obligation to write responsibly to and in relation to locally and globally situated others, in public and professional contexts. Nevertheless, on this view, a writer has always alsoto be a different reader, in other words a self-critical and reflexive reader of her own and others' writing practices, aware of the ways in which textual meanings and interpretations are contestable and transformable.

Political sociologist Gerard Delanty uses the term critical cosmopolitanism to conceptualise the social world 'as an open horizon in which new cultural models take shape' (Delanty 2006: 27). The reflexive, critical and dialogic disposition of this process is reinforced in reference to that dimension of cosmopolitanism involving 'the creation and articulation of communicative models of world openness in which societies undergo transformation' (Delanty 2006: 35; see also 2009: 251-52). The centrality of communicating to the process of inhabiting a critical cosmopolitan stance suggests the significance of understanding and evaluating writing in relation to this ongoing project, particularly since writing practices, as means of forging connections with the lives and worlds of others, have a potential reach and impact unimaginable just a couple of decades ago.

Writing and the texts to which it gives rise are each inseparable from the material spaces and temporalities in which writing is developed and texts disseminated. Writing also constitutes a form of human subjectivity, however disguised that may be, since it necessarily addresses the other, even when indirectly, unwittingly or unwillingly. This pivotal, relational dimension of language calls up the ethical, and therefore the questions of a writer's obligations. In a cosmopolitan framework, the dialectical tensions between several and perhaps rival responsibilities to different (known and unknown) others becomes ever more part of the question of communicative practices in general and writing in particular. Thus, I argue for writing as figuring the (mostly ambivalent) ethical connections and relationships that obtain between self and other.

Writing responsibly in a cosmopolitan context demands the use of imagination: the capacity to think and feel and respond virtually, beyond one's own time and place and into another's. It involves reading between the lines, transgressing borders: inscribing and reading a world and set of relationships that may capture but must also exceed our immediate context and concerns, the taken-for-granted ways of our particular culture, the familiarity and predictability of our face-to-face encounters. Seen in this way, the act of imagining, one could argue, is thus inherently cosmopolitan. Scholars including Beck (2002), Delanty (2009) and Appiah (2006), have also recognised the vital contribution imagination makes to the cosmopolitan project. Beck identifies the defining feature of the cosmopolitan perspective as the 'dialogic imagination'. He explains this as:

the clash of cultures and rationalities within one's own life, the "internalized other". The dialogic imagination corresponds to the coexistence of rival ways of life in the individual experience, which makes it a matter of fate to compare, reflect, criticize, understand, combine contradictory certainties. (Beck 2002: 18) 
Not dissimilarly, Delanty uses the term 'cosmopolitan imagination' to describe 'a view of society as an ongoing process of self-constitution through the continuous opening up of new perspectives in light of the encounter with the Other' (Delanty 2009: 13). Here, imagining (alternative) relations between self and other, local and global provokes the potential for mutual transformation. By extension, 'it is out of the interaction of societies, communities, individuals from different cultures that the cosmopolitan imagination is generated' (Delanty 2009: 77-79). This necessarily involves a tension, 'a dynamic relation between the local and the global' (2009: 68). Where Delanty uses 'translation' as a metaphor for describing the changes that might be effected though forging (imaginative) connections with others $(2009,13)$, Appiah uses the term 'conversation' He intends it both literally, as 'talk', and metaphorically, 'for engagement with the experience and the ideas of others' (Appiah 2006: 85). He refers to the role of the imagination in the process of conversation and, though he doesn't elaborate, we might infer that he suggests the way in which we need to go beyond ourselves, beyond the conventions of our social and temporal positions to be responsive to the other. He also remarks that our connections made in the imagination 'are among the realest connections that we have' (2006: 135). In these accounts, the significance of the communicative dimension is clear and, for writers, highlights the ways in which imagination and language may be combined to enrich (or, of course, possibly impoverish) understandings of, particularly unknown, others. Opening up to the other, the cosmopolitan imagination has the potential to navigate the social, geographical and cultural differences between ourselves and others, through feelings of empathy, and to heighten our awareness of our obligations within as well as beyond familiar territories and temporalities.

\section{Folding in an ethics of care}

In writing in the public domain, when we imagine, our emotional, empathetic and evaluative envisioning will be situated by, and often find itself in dialectical tension with, specific instrumentally driven economic, political, cultural, technological and communicative considerations. Given the bias of globalisation towards such rationalist approaches, care is therefore needed to redress the balance and ensure that the human, the social and the environmental are not displaced. A critical cosmopolitanism that incorporates the practice and value of a feminist ethics of care (and the latter's insistence on the ties of interdependence and responsibility that underpin our relations with others) is, in my view, crucial in grounding cosmopolitanism in the human, social realm.

Feminist scholars Virginia Held and Fiona Robinson extend the ethics of care into the global arena. Their work thus represents what I read as a specifically imaginative expression of a grounded cosmopolitanism. A feminist ethics of care treats human beings 'not as autonomous subjects, but as being embedded in networks and relationships of care' (Robinson 2009). Held, who sees people always and everywhere as 'relational and interdependent' (Held 2006: 156), argues that an ethics of care helps highlight the connections between people as emotionally rich and mutually sustaining relations of interdependence, not as exclusively rationally based or as centred on the lone individual (or self-contained person or private organisation or single society). It is the emotions, such as empathy, sensitivity and responsiveness, that are better guides to what we should or shouldn't do, in moral terms (2006: 157). As practice and as a value, an ethics of care:

advocates attention to particulars, appreciation of context, narrative understanding, and communication and dialogue in moral deliberation, suspecting that the more general and abstract the recommendation, the less adequate for actual guidance. (Held 2006: 157-8)

Here, then, we again see an explicit role for language in the activities of and commitment to care, which, by extension, raises some important questions for writers and writing. How might we re-imagine our writing practices, so as to communicate in a language that admits writing itself as one means of acknowledging our interdependence (however conflicted or difficult) with and responsibility to others? Even if we write for a targeted readership, how should our writing take account of the larger ramifications of our texts for other people, places and times? In relation to unknown (or distant and different) others, how should we imagine and negotiate, through our writing, our obligations to communicate carefully in relation to those others? How does situating our texts in a global context result in them meaning differently, being interpreted otherwise, and how far does our writing allow for those possibilities? In other words, how do the discourses and the rhetoric we deploy expand or shrink the horizons of our interactions with or in reference to others?

Therefore, a key challenge in our evaluating and in our doing of writing in contemporary professional and public contexts is not merely to affirm or reaffirm the 'I' or the 'we' (in the face of the other) - which may often be the impulse and the prerogative of voices competing for attention in a consumerist and aggressively promotional western culture. It is, rather, to recognise, through writing approaches and practices, how we are constituted or can re-imagine ourselves as involved simultaneously in a complex of global and local networks, with obligations to others situated far as well as near, then as well as now. In this spirit, writing has the potential to constitute a resistance to the dehumanising and decontextualising effects of a market economy-driven globalisation.

The following section explores how, as one way of scrutinizing the cosmopolitan potential of writing practices, a political text may be troubled or resisted by the text of a literary work.

\section{Approach}

My method of reading 'No to people smuggling' and Hand me down world alongside each other, especially given that they are clearly distinct in terms of genre and function, has been stimulated by the work of French theorist Jacques Rancière. Rancière is concerned with problematising the ontological status of the conventional and normative tendency to define and fix boundaries between genres, disciplines, and discourses. He remarks: 
Thinking for me is always a rethinking. It is an activity that displaces an object away from the site of its original appearance or attending discourse. Thinking means to submit an object of thought to a specific variation that includes a shift in its discursive register, its universe of reference, or its temporal designations. (Panagia \& Rancière 2000: 120)

Literature, which for Rancière can constitute a subversive democratic space, offers just such 'a specific variation' to the mainstream social domain of politics. The principle of literature's form of politics, he claims:

is to leave the common stage of the conflict of wills in order to investigate in the underground of society and read the symptoms of history. It takes social situations and characters away from their everyday, earth-bound reality and displays what they truly are, a phantasmagoric fabric of poetic signs, which are historical symptoms as well. For their nature as poetic signs is the same as their nature as historical results and political symptoms. (Rancière 2004: 19-20)

It is in this way, that is, through the space offered by literature to explore historical and political symptoms as poetic signs, that literature 'does a kind of side-politics or meta-politics' (2004: 19), as mentioned above. The words, the concepts and the discourses mobilised in political communication are shown to have the potential to mean differently and enable us to apprehend their impact differently when used and reviewed in other (for instance, literary) contexts and for other (for instance aesthetic and ethical) purposes. And so, I want to show, this act of re-evaluating the writing of those words, concepts and discourses produced for the domain of political communication in terms of their writing in literature engenders precisely the cosmopolitan potential for transformation.

\section{'No to people smuggling' and Hand me down world}

Myriad forms of writing relating to migration across borders - fiction and non-fiction, political, corporate and community, formal, bureaucratic and vernacular - now circulate across local and global territories, and proliferate via a range of platforms. In turn, in a culture of visuality, the concept as well as the tropes and practices of seeing become ways of knowing and responding to others, by imagining our relative closeness to, distance from, and responsibilities to care in relation to them. Writing is deeply immersed in and implicated in this culture, such as in its harnessing of metaphors of seeing, via its ubiquitous juxtaposition with visual images, and in its deployment of the word as image. In this section I aim to show how matters of seeing, vision and visuality are central to textual representations (in diverse genres) of asylum seekers. In turn, and taking a critical cosmopolitan perspective, I examine how such notions, variously teased out in fiction, can challenge us to reappraise the strategies and aims of political writing.

Although most asylum seekers come to Australia by plane, the poorest and most desperate of them arrive by more newsworthy and visually spectacular means - boat. Australia, despite its mixed history of accepting new arrivals, has traditionally prided itself on welcoming migrants and refugees from the UK, Europe and Asia in particular (see Department of Immigration and Multicultural Affairs 2001; Richards 2008). Hence, the target of blame for the most recent asylum seeker arrivals (such as from Afghanistan, Iraq and Iran) has become the 'people smugglers', or those people whom the refugees pay to arrange their passage to Australia's shores. In 2010 the Federal Government launched an exclusive YouTube campaign, entitled 'No to people smuggling', 'an initiative to raise awareness and educate communities within Australia about the dangers and uncertainties of using people smugglers' (Australian Government 2010). Despite being nominally aimed at 'communities within Australia', the campaign is, of course, of more relevance to non-Australians, those who live outside the country.

The series, comprising individual short filmic narrative clips, added to progressively, not only in English but in Farsi, Tamil, Arabic, Sinhalese, Pashto and Dari, ranges from a distressing account of an asylum seeker drowning at sea (which I discuss at greater length below) to first-person accounts of the experience of arriving by boat and the detention and return to home-country process.

Although in each film the Government's rhetoric is quite deliberately strident and dogmatic, if we are alert to alternative, competing (including fictional) narratives about asylum seekers, the ambivalence of its discourse is also palpable and alternatively legible, as we take the time to reflect on its resonances (with other related texts) and repercussions (in terms of its impacts on, and our responsibility to care for, the other). In other words a critical cosmopolitan orientation to the text (grounded in an ethical and imaginative sensibility) disrupts its function and deflects its apparent purpose to transmit a 'simple' univocal policy message.

In the confronting and powerful video I refer to, a 31-second clip entitled 'Left Behind' (Australian Government 2010), the camera takes the view of a lone individual drowning in the far ocean; there is no landmark in sight. The vision is of grey, vicious waves whipping and curling; there is an intermittent glimpse of sky before the imagined body goes under water. We hear the waves sloshing (against and sometimes above the invisible person behind the camera lens). And we hear too the choking and spluttering gasps of a drowning person, a language interpretable by all of us, as the text below, one line at a time, plays across the screen:

No one knows where you are

No one can hear you

No one should go through this

No one can trust a people smuggler

No to people smuggling. (Australian Government 2010) 
On one level the video works as a graphically direct piece of government propaganda. It uses image, text and sound to create a shocking narrative bite and to engender a sense of fear in its intended viewers. Moreover, the words work both as line-by-line slogans and as a cumulative catch-cry of proscription and deterrence, aimed at directing the reader's interpretation of the significance of the visual and aural texts.

New Zealander Lloyd Jones's novel Hand me down world was also published in 2010, just a few months after the 'No to people smuggling' online campaign was launched. This highly acclaimed work of fiction tells of the journey of a young woman, Ines, from Africa to Europe in search of her abducted son. She sails on a boat that 'stank of fish' (Jones 2010: 20), a passage paid for by money she has earned from 'hotel sex with foreigners' (Jones 2010: 20). Like the absent body in the video clip, Ines is fearful for her life; she nearly drowns. And in the same way that people smugglers are identified as untrustworthy in the campaign, so does Ines discover that they are, when she is (against what she has been promised) abandoned in the water still some considerable distance from the Sicilian shoreline.

The first part of the narrative is related as a series of 'testimonies' about Ines given by different characters to the police in the latter's efforts to locate and charge Ines for the death of a woman in Sicily. These characters have encountered Ines, a determined and aloof character, on her travels from the Four Seasons Hotel on the Arabian Sea to another hotel in Tunisia and then by sea to Italy, across the Alps and finally to Germany, where her son Daniel lives with his father, Jermayne, and his adoptive mother, Abebi. Only in the second part do we read the narrative from Ines' perspective, her account contradicting aspects of the individual testimonies given by others. Thus, Hand me down world refuses the reductiveness of the single story (see Adichie 2009), offering instead a multi-faceted collage of characters' musings, and different versions of events, exchanges, and responses to their experiences. A significant portion of the novel is set in Berlin, which is evoked as a multicultural centre, a city on the move, teeming with tourists and vagabonds, residents and itinerants. The feelings of doubt, fear and suspicion of the unknown, foreign and marginalised other are given voice in the testimonies, as individual characters offer up their sometimes harsh, sometimes sympathetic impressions of Ines (and, eventually, she of them) as she passes through their lives. Characters belong or don't belong, depending on the realms - spaces and temporalities - in which they move; they are visible or go unnoticed; they look and see different things. They are alienated from one another in some senses and intimately tied to one another, whether willingly or unwillingly, in others.

However, the text writes so much more than this crude and partial plot and theme summary implies, even though its narrative comprises a language that is spare and unsentimental. From the outset, as readers we know we are moving in different imaginative territory when we read the following:

How long was she in the water? What is time under those circumstances? What is an hour? What is ten minutes? Time can be measured in other ways. By the cold. By fear. By the length of time it takes for flesh to turn numb and then to rot and come away from her bones. (Jones 2010: 22)

By thus suggesting we shift our understanding of time from an objective phenomenon to a subjective and embodied set of responses to a specific environment, the text asks us to consider Ines's experience as a story we might ourselves, at least imaginatively, share, and thus care about. By extension, the narrative (whose key figures relate to sight and modes of seeing) suggests that rather than seeing (making sense of) something - whether event, circumstance or encounter - as being 'out there', and distinct from us, we might instead see it, and whoever it involves, in relation to ourselves, and thus in terms of our shared responsibility for its impacts. This is not to assimilate others' experiences into our own, but rather to recognise both their difference from and also their correspondence with our own horizons of meanings and value.

Even the government text, whose rhetoric aims to achieve a reinforcement of the us-them difference as oppositional rather than relational, fails to secure that distinction. While the written text is addressed to the 'you', the perspective taken on the visual text by the camera is actually from the very position of that 'you' - who therefore 'we', as readers of the video clip (would-be asylum seekers, citizens and non-citizens), also share. The seeing is thereby essentially inter-subjective. The borders and the boundaries between 'we' and 'you' are blurred, perhaps in the way that Beck suggests the new grammar of cosmopolitanism operates:

Even the most popular of personal pronouns, the mystical and menacing 'we', has lost much of its global public appeal. Indeed one could say that the dissolution of the national idiom is shown not least by the disenchantment of the 'we': which 'we' do we mean when we speak of the 'we'? The revaluation and inversion of the obviousness of 'we'-assertions in the national axiomatic into ever more unanswerable 'we'-questions shows how fundamentally the nature of the 'we' has been problematised. (Beck 2006: 70)

Nonetheless, and despite Beck's claims, it would be naïve to suggest that mainstream nationalist discourses have lost their parochial focus. And visual images are still frequently mobilised to reinforce the otherness of the other (as Campbell (2007), Silverstone (2007) and Robertson (2010), for example, have so forcefully pointed out in their respective work). However, from a critical cosmopolitan perspective, such entrenched positions are impossible to sustain. If we look again at the video clip we notice that the first two lines of written text flashed onto the screen - 'No one knows where you are/ No one can hear you' - are overlaid on the moving visual image of a vicious ocean and are in dissonance with the audio of the drowning call for help, which of course we cannot fail to hear. This moment highlights the visuality-care nexus and underscores a tension between the way in which the government's monological political "messaging" would wish readers to make sense of its campaign, and the alternative understandings that readers may derive from a critical cosmopolitan perspective. 
The government's 'Left behind' text assumes a reader whose viewing (and interpretive) practices conform to those that Ines in Hand me down world refers to in her observations of a man she meets in Berlin: 'so many people in the world are like [him]. They lean on the safety rail and watch with horror the pain of others' (Jones 2010: 293). This kind of viewing, we might infer from the narrative, stymies our capacity to care, since we can be almost literally enraptured by the suffering of others, maintaining a safe emotional and empathetic distance from them in the effort to protect ourselves. And yet, as the narrative of Hand me down world also suggests, seeing is a physical but importantly an imaginative, relational capacity as well. For example, in the novel, Hannah, one of the characters who offers a testimony on Ines, relates how she became frustrated when Ralf, her former husband (for whom Ines works in Berlin) who is blind, requests that she (Hannah) describe repeatedly, and in minute detail, the contents of a photograph taken by Ralf's father during the second world war, depicting hundreds of dead bodies of Jews massacred during the Holocaust. Hannah recounts how after several weeks of going through this process she acquired 'a statistical frame of mind... I no longer saw the bodies of the individuals they were ... I had arrived at the same place and the same frame of mind that accommodates the dispassionate eye' (Jones 2010: 102). In mainstream western culture, and in 'No to people smuggling', this apparently objective observing eye (I) is similarly cultivated, both by our familiarity with and habit of being confronted with horrific images, and by our thrall to a widespread 'statistical' or rationalist position that reads interdependence as weakness and vulnerability, and that resists reflection on the complex and ambivalent relations of responsibility to care for distant or unknown others.

The Australian government's approach to its campaign certainly seems to assume this latter disposition in its readers. In the film, the third line of text does in fact introduce the ostensible voice of care, with the acknowledgement that 'no one should go through this'. However the (writer's and, by implication, reader's) responsibility to care is swiftly deflected by transposing the culpability for the asylum seeker's plight onto the people smuggler: 'no one can trust a people smuggler / no to people smuggling'. This rhetorical move distracts attention from an ethically imaginative narrative about why someone might make such a journey, and how 'we' all might bear some responsibility for their welfare.

From a critical cosmopolitan perspective, however, the attempt to marshal a specific response by the selection and combination of text, image and sound to create a unified political message mediated via YouTube is undermined, precisely because it overlooks the possibility of the meaningful interaction between reader and text and the imaginative, relational connection forged between the text's 'you' and we who are viewing your plight that is, our plight.

\section{Conclusion}

A critical cosmopolitan perspective on writing and reading practices helps us to see the porous borders, not only of language, syntax and meaning, but also of text and image. In a globalised culture of visuality, we thus have the capacity to understand the human subject crossing borders differently, aware that we are directly implicated and involved in what and how we see, and thus understanding that we are challenged with (though we may refuse) the responsibility to care. Given this scenario, writers of political campaigns that attempt to monopolise or dictate to readers a singular view of the world are wilfully misguided.

In the spirit of disturbing borders, a critical cosmopolitan approach also shows how fiction writing can dislocate the borders of political writing, helping us to question the latter's propriety, conventions and ethical impacts. Or, as Shafak observes, 'stories cannot demolish frontiers, but they can punch holes in our mental walls. And through those holes, we can get a glimpse of the other, and sometimes even like what we see' (Shafak 2010). Moreover, in an environment in which the abstract media bite - whether text, vision or sound - dominates the public space, fiction writing has a particularly important intervention to make. As an extended narrative, which may encourage in the reader a contextualised, relational understanding of the complex interactions between people, places and events in time, fiction writing can invoke a richer appreciation of how we might imagine, and respond with care to, the world of others.

Neither politics nor art is equivalent or reducible to the other, but each can be enhanced and transformed by intertextual reference to the other. This involves a self-conscious, imaginative, cosmopolitan move that writers (and readers) might make in order to transform both politics and art (texts) beyond what they are designated to be to what they might become.

\section{Notes}

[1] This paper is not arguing for recognition of the political dimensions of literature, or for literature as political. Rather, it argues for the value of writing and reading literature as a means of enabling us to reflect on, critique and revise our own writing practices in public - political, organisational, corporate and community - domains. return to text

[2] Fisher's article poses the question 'In what way can a work of art be political?' - a question different from that I pose in this paper, but nonetheless pertinent to its interests. He examines artist Francis Alÿs's tracing the 'green line' that marked the division between east and west Jerusalem, drawn by Moshe Dayan, Israeli military leader and statesman, in 1949. Over two days, Alÿs walked the terrain of Jerusalem, 'leaking along the path behind him a thin drizzle of green paint ... reinscribing the original act of partition through a performative act of iteration. In doing so he was opening up the undeniable ambiguity of the "margin", at once both real and imagined, created by the arbitrary thickness of Dayan's pencil' (Fisher 2011: 2). return to text

[3] Jordan Williams and Jen Webb pursue a tangential enquiry, in their discussion about the ways in which 'creative works can bring into consciousness and hence into social awareness things that might otherwise be overlooked, or be differently framed'. They also 


\section{Anne Surma TEXT Vol 17 No 1}

report on their survey investigating the extent to which human-rights related issues were being taken up in Australian creative outputs during 2003 and 2004 (Williams \& Webb 2008). return to text

[4] Of course, other fictional texts might make alternatively rich critical cosmopolitan interventions into current political debates. Staying on the topic of asylum seekers, migration and people in transit, we might look at Michelle de Kretser's brilliant and sometimes acerbic observations about mainstream attitudes towards, as well as the subjective perspective of, the asylum seeker in Questions of travel (2012). return to text

[5] In a similar vein, Nikos Papastergiadis's remarks that 'while artists do not have the answers to the issues that we face in the world, they have developed techniques for finding the questions with which they can cross-examine the perplexity of our common condition' (Papastergiadis 2007: 150). return to text

[6] Elements of the discussion that follows draw on and adapt material from my monograph, Imagining the cosmopolitan in public and professional writing (Surma 2013). The book explores how professional writing in political, corporate, organisational and community domains variously positions us in the world, and how, in a context of globalization, writers are accountable for the ways in which their writing aims to forge connections (or avow disconnection) between self and other within and across borders of various kinds. I investigate how writers working in contemporary environments might navigate, through critical reflection and deliberation, the times, the spaces and the borders or margins that influence and shape the texts they produce in their communicating with others. While the book suggests that there is much professional writers (of non-fiction) might gain from exploring closely the language and meaningmaking practices of their fiction-writing colleagues, it does not develop the proposition. This paper begins addressing that gap. return to text

\section{Works cited}

Adichie CN 2012 'To instruct and delight: A case for realist literature', Commonwealth Lecture: http://www.commonwealthfoundation.com/sites/cwf/files/downloads/Commonwealth_Lecture 2012 Chimamanda Ngozi_Adichie.pdf (accessed 28 February 2013) return to text

Adichie, CN 2009 'The danger of a single story', TED Talks:

http://www.ted.com/talks/chimamanda_adichie_the_danger_of_a_single_story.html (accessed 28 February 2013) return to text

Appiah, KA 2006 Cosmopolitanism: Ethics in a world of strangers, Penguin, London return to text

Australian Government 2010 'No to people smuggling', YouTube campaign: http://www.youtube.com/user/notopeoplesmuggling (accessed 28 February 2013) return to text

Beck, U 2006 The cosmopolitan vision, trans C Cronin, Polity Press, Cambridge return to text

Beck, U 2002 'The Cosmopolitan society and its enemies', Theory, Culture \& Society 19, 1-2: 17-44 return to text

Campbell, D 2007 'Geopolitics and visuality: Sighting the Darfur conflict', Political Geography 26: 357-382 return to text

de Kretser, M 2012 Questions of travel, Allen \& Unwin, Crows Nest, NSW return to text

Delanty, G 2009 The cosmopolitan imagination: The renewal of critical social theory, Cambridge University Press, Cambridge return to text

Delanty, G 2006 'The cosmopolitan imagination: Critical cosmopolitanism and social theory', British Journal of Sociology 57, 1: 25-47 return to text

Department of Immigration and Multicultural Affairs 2001 Immigration: Federation to century's end, Commonwealth of Australia, Canberra, ACT: http://www.immi.gov.au/media/publications/statistics/federation/federation.pdf (accessed 28 February 2013 ) return to text

Fisher T 2011 'Aesthetics and the political: An essay on Francis Alÿs's green line', Cultural Critique 78, 1-26 return to text

Havel V 1990 [1989] 'Words on words', The New York review of books: http://www.nybooks.com/articles/archives/1990/jan/18/wordson-words/?pagination=false (accessed 28 February 2013) return to text

Held, V 2006 The ethics of care: Personal, political and global, Oxford University Press, Oxford \& New York return to text

Jones, L 2010 Hand me down world, Text Publishing, Melbourne return to text

Panagia D \& J Rancière 2000 'Dissenting words: A conversation with Jacques Rancière', Diacritics 30, 2: 113-126 return to text

Papastergiadis, N 2012 ‘Aesthetic cosmopolitanism’, in G Delanty (ed), Routledge handbook of cosmopolitan studies, Routledge, Abingdon, Oxon and New York: 220-32 return to text

Papastergiadis, N 2007 'Glimpses of cosmopolitanism in the hospitality of art', European Journal of Social Theory 10, 1: 139-152 return to text

Rancière, J 2004 'The Politics of Literature', SubStance 33, 1: 10-24 return to text

Richards, E 2008 Destination Australia: Migration to Australia since 1901, University of New South Wales Press, Sydney, NSW return to text

Robertson, A 2010 Mediated cosmopolitanism: The world of television news, Polity Press, Cambridge and Malden, MA return to text

Robinson, F 1999 Globalizing care: Ethics, feminist theory and international relations, Westview Press, Boulder, CO \& Oxford return to text

Shafak, E 2010 'The politics of fiction', TED Talks: http://www.ted.com/talks/elif_shafak_the_politics_of_fiction.html (accessed 28 February 2013) return to text

Silverstone, R 2007 Media and morality: On the rise of the mediapolis, Polity Press, Cambridge \& Malden, MA return to text 
Smith Z 2009 'Speaking in tongues', The New York Review of Books: http://www.nybooks.com/articles/archives/2009/feb/26/speakingin-tongues-2/?pagination=false (accessed 28 February 2013) return to text

Surma A 2013 Imagining the cosmopolitan in public and professional writing, Palgrave Macmillan, Basingstoke, Hants return to text

Williams, J \& J Webb 2008 'Writing/rights: creative practice and political action', TEXT 12, 1:

http://www.textjournal.com.au/april08/williams_webb.htm (accessed 28 February 2013) return to text

Dr Anne Surma is a senior lecturer in the School of Social Sciences and Humanities at Murdoch University in Western Australia. Her first book, Public and Professional Writing: Ethics, Imagination and Rhetoric (Palgrave 2005), laid the ground for her interest in contemporary writing theory and practice. Her more recent research has explored writing through a critical cosmopolitan lens, as reflected in her monograph, Imagining the Cosmopolitan in Public and Professional Writing (Palgrave 2013).

TEXT

Vol 17 No 1 April 2013

http://www.textjournal.com.au

General Editor: Nigel Krauth. Editors: Kevin Brophy \& Enza Gandolfo

text@textjournal.com.au 